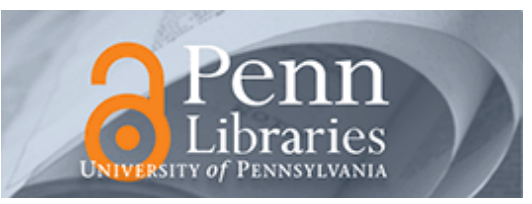

University of Pennsylvania

ScholarlyCommons

August 2008

\title{
The inhibition of Staphylococcus epidermidis biofilm formation by vancomycinmodified titanium alloy and implications for the treatment of periprosthetic infection
}

\author{
Valentin Antoci Jr. \\ Thomas Jefferson University \\ Christopher S. Adams \\ Thomas Jefferson University \\ Javad Parvizi \\ Thomas Jefferson University \\ Helen M. Davidson \\ Thomas Jefferson University \\ Russell J. Composto \\ University of Pennsylvania, composto@Irsm.upenn.edu
}

See next page for additional authors

Follow this and additional works at: https://repository.upenn.edu/be_papers

\section{Recommended Citation}

Antoci, V., Adams, C. S., Parvizi, J., Davidson, H. M., Composto, R. J., Freeman, T. A., Wickstrom, E., Ducheyne, P., Jungkind, D., Shapiro, I. M., \& Hickok, N. J. (2008). The inhibition of Staphylococcus epidermidis biofilm formation by vancomycinmodified titanium alloy and implications for the treatment of periprosthetic infection. Retrieved from https://repository.upenn.edu/be_papers/127

Pre-print version. Published in Biomaterials, August 2008.

Publisher URL: http://dx.doi.org/10.1016/j.biomaterials.2008.08.016

This paper is posted at ScholarlyCommons. https://repository.upenn.edu/be_papers/127

For more information, please contact repository@pobox.upenn.edu. 


\title{
The inhibition of Staphylococcus epidermidis biofilm formation by vancomycinmodified titanium alloy and implications for the treatment of periprosthetic infection
}

\begin{abstract}
Peri-prosthetic infections are notoriously difficult to treat as the biomaterial implant is ideal for bacterial adhesion and biofilm formation, resulting in decreased antibiotic sensitivity. Previously, we reported that vancomycin covalently attached to a Ti alloy surface (Vanc-Ti) could prevent bacterial colonization. Herein we examine the effect of this Vanc-Ti surface on Staphylococci epidermidis, a Gram-positive organism prevalent in orthopaedic infections. By direct colony counting and fluorescent visualization of live bacteria, $S$. epidermidis colonization was significantly inhibited on Vanc-Ti implants. In contrast, the gram-negative organism Escherichia coli readily colonized the Vanc-Ti rod, suggesting retention of antibiotic specificity. By histochemical and SEM analysis, Vanc-Ti prevented S. epidermidis biofilm formation, even in the presence of serum. Furthermore, when challenged multiple times with $S$. epidermidis, Vanc-Ti rods resisted bacterial colonization. Finally, when S. epidermidis was continuously cultured in the presence of Vanc-Ti, the bacteria maintained a Vanc sensitivity equivalent to the parent strain. These findings indicate that antibiotic derivatization of implants can result in a surface that can resist bacterial colonization. This technology holds great promise for the prevention and treatment of periprosthetic infections.
\end{abstract}

\section{Keywords}

antibacterial, bacterial adhesion, biofilm metal, surface treatment, bacteria, surface modification, titanium alloy

\section{Comments}

Pre-print version. Published in Biomaterials, August 2008.

Publisher URL: http://dx.doi.org/10.1016/j.biomaterials.2008.08.016

\section{Author(s)}

Valentin Antoci Jr., Christopher S. Adams, Javad Parvizi, Helen M. Davidson, Russell J. Composto, Theresa A. Freeman, Eric Wickstrom, Paul Ducheyne, Donald Jungkind, Irving M. Shapiro, and Noreen J. Hickok 


\title{
The inhibition of Staphylococcus epidermidis biofilm formation by vancomycin- modified titanium alloy and implications for the treatment of periprosthetic infection
}

\author{
Valentin Antoci, Jr. ${ }^{\text {a }}$, Christopher S. Adams ${ }^{\text {a }}$, Javad Parvizi ${ }^{\text {a,b }}$, Helen M. Davidson ${ }^{\text {a }}$, \\ Russell J. Composto ${ }^{c, d}$, Theresa A. Freeman ${ }^{a}$, Eric Wickstrom ${ }^{\mathrm{e}}$, Paul Ducheyne ${ }^{\mathrm{c}, \mathrm{f}}$, \\ Donald Jungkind $^{\mathrm{g}}$, Irving M. Shapiro ${ }^{\mathrm{a}, \mathrm{c}, \mathrm{e}}$, Noreen J. Hickok ${ }^{\mathrm{a}, \mathrm{e}, *}$ \\ a Department of Orthopaedic Surgery, Thomas Jefferson University, Philadelphia, PA, USA \\ ${ }^{\mathrm{b}}$ The Rothman Institute, Philadelphia, PA, USA \\ ${ }^{\mathrm{c}}$ Center for Bioactive Materials and Tissue Engineering, School of Engineering and Applied Science, University of Pennsylvania, Philadelphia, PA, USA \\ ${ }^{\mathrm{d}}$ Department of Materials Science E Engineering, University of Pennsylvania, Philadelphia, PA, USA \\ e Department of Biochemistry and Molecular Biology, Thomas Jefferson University, USA \\ ${ }^{\mathrm{f}}$ Department of Bioengineering, University of Pennsylvania, Philadelphia, PA, USA \\ ${ }^{\mathrm{g}}$ Department Pathology, Anatomy, and Cell Biology Thomas Jefferson University, Philadelphia, PA, USA
}

\section{A R T I C L E I N F O}

\section{Article history:}

Received 29 April 2008

Accepted 4 August 2008

Available online $\mathrm{xxx}$

\section{Keywords:}

Antibacterial

Bacterial adhesion

Biofilm

Metal surface treatment

Bacteria

Surface modification

Titanium alloy

\begin{abstract}
A B S T R A C T
Peri-prosthetic infections are notoriously difficult to treat as the biomaterial implant is ideal for bacterial adhesion and biofilm formation, resulting in decreased antibiotic sensitivity. Previously, we reported that vancomycin covalently attached to a Ti alloy surface (Vanc-Ti) could prevent bacterial colonization. Herein we examine the effect of this Vanc-Ti surface on Staphylococci epidermidis, a Gram-positive organism prevalent in orthopaedic infections. By direct colony counting and fluorescent visualization of live bacteria, S. epidermidis colonization was significantly inhibited on Vanc-Ti implants. In contrast, the gram-negative organism Escherichia coli readily colonized the Vanc-Ti rod, suggesting retention of antibiotic specificity. By histochemical and SEM analysis, Vanc-Ti prevented S. epidermidis biofilm formation, even in the presence of serum. Furthermore, when challenged multiple times with S. epidermidis, Vanc-Ti rods resisted bacterial colonization. Finally, when S. epidermidis was continuously cultured in the presence of Vanc-Ti, the bacteria maintained a Vanc sensitivity equivalent to the parent strain. These findings indicate that antibiotic derivatization of implants can result in a surface that can resist bacterial colonization. This technology holds great promise for the prevention and treatment of periprosthetic infections.
\end{abstract}

(c) 2008 Elsevier Ltd. All rights reserved.

\section{Introduction}

Implant surfaces serve as ideal substrates for bacterial colonization. This colonization often results in periprosthetic infection (PPI), a condition that leads to destruction of local tissues, patient disability and morbidity, and on occasion, death [1]. The implant surface accumulates serum proteins which promote bacterial adherence and colonization [2], and serves as a critical first step in the development of PPI. The adherent bacteria synthesize a complex glycocalyx that enmeshes the bacteria and provides

\footnotetext{
* Corresponding author. Department of Orthopaedic Surgery, Thomas Jefferson University, 1015 Walnut Street, Suite 501, Philadelphia, PA 19107, USA. Tel.: +1 215 955 6979; fax: +12159559159.

E-mail address: noreen.hickok@jefferson.edu (N.J. Hickok).
}

escape for them from immune surveillance or antibiotic treatment [3-7]. Currently, PPI treatment requires removal of the contaminated implant coupled with extensive bone debridement, excision of infected tissues and bone, and prolonged antimicrobial treatment [8].

Various antimicrobial materials have been developed to counter this implant-associated infection. The gold standard for targeted local delivery of antimicrobial agents is antibiotic-impregnated bone cement (polymethylmethacrylate - PMMA); other antibioticimpregnated biodegradable carriers such as sol-gel coatings $[9,10]$ and hydrogels $[11,12]$ are under development. The use of antibiotic loaded PMMA allows delivery of high concentrations of antibiotics to the affected area without causing systemic toxicity. There are, however, numerous problems with the current local antibiotic delivery systems. First, most local antibiotic delivery systems are, by their nature, targeted to initiate treatment upon implantation, 
with levels of eluted drug remaining high for a well-defined period. Subsequently, the elution of antibiotics falls below the minimal inhibitory concentration for a longer period, a situation that could result in emergence of resistant organisms. Second, the drug delivery is ineffective in penetrating to the bacteria embedded within the biofilm on the implant surface. Finally, addition of many antibiotics to PMMA is not possible as the exothermic reaction caused by curing of the cement results in heat inactivation of the drug $[13,14]$.

Attachment of bacteria to the implant surface appears to be the initial and the most critical step in development of PPI and hence, we and other investigators have invested extensive efforts to prevent bacterial adherence. We have previously reported that covalently bonding antibiotics to a metal implant surface can inhibit bacterial attachment. This antibiotic-derivatized surface is stable in the face of Staphylococcus aureus (S. aureus) challenges and prevents its colonization [15]. In this report, we examine the effect of this surface on a strain of Staphylococcus epidermidis (S. epidermidis, ATCC ${ }^{\mathrm{TM}} 155^{\circledR}$ ), an organism that is prevalent in orthopaedic infections and notorious for forming biofilms. Furthermore, we evaluate the ability of this surface to prevent bacterial colonization in the presence of serum proteins. Results of the study indicate that derivatization of implant surfaces with antibiotics may provide a practical approach to inhibiting bacterial colonization of implants and thereby minimizing PPI.

\section{Materials and methods}

\subsection{Experimental design}

Colonization of the surface of vancomycin-modified Ti alloy (Ti90Al6V4) rods (Vanc-Ti) by S. epidermidis was evaluated. We chose Ti90Al6V4 for these studies as it is commonly used for manufacturing orthopedic implants. Surface colonization was measured by determining the numbers of S. epidermidis colony forming units (cfu) adherent to the rods and by treatment of the surface with a vital stain. In parallel, S. epidermidis colonization of the surface was visualized using scanning electron microscopy (SEM), currently the gold standard for biofilm detection. The specificity of inhibition was evaluated using the gram negative organism $E$. coli, an organism that is not sensitive to this antibiotic. Finally, we determined if there was emergence of resistant strains of S. epidermidis on the Vanc-Ti rods following multiple bacterial challenges.

\subsection{Antibiotic modification of Ti alloy}

One mm diameter Ti90Al6V4 wire (Ti alloy, Goodfellow, Cambridge, UK) was passivated with $\mathrm{H}_{2} \mathrm{O}_{2} / \mathrm{H}_{2} \mathrm{SO}_{4}$ and aminopropylated under argon using $5 \%(\mathrm{v} / \mathrm{v})$ aminopropyl-triethoxysilane in anhydrous toluene. It was coupled sequentially with two Fmoc-[2-(2-amino-ethoxy)-ethoxy]-acetic acid (AEEA) linkers and vancomycin in the presence of O-(7-azabenzo-triazole-1-yl)-1,1,3,3-tetramethyluronium hexafluorophosphate (HATU); between each addition, deprotection was achieved with $20 \%$ piperidine in $\mathrm{N}, \mathrm{N}$-dimethylformamide [15-17].

\subsection{Evaluation of surface colonization}

Control and Vanc-Ti rods (5-10 $\mathrm{mm} \times 1 \mathrm{~mm}$ ) were weighed, sterilized with $70 \%$ EtOH for 15 min, and washed twice with BBL ${ }^{\mathrm{TM}}$ Trypticase ${ }^{\mathrm{TM}}$ Soy Broth (TSB, BD Bioscience). S. epidermidis ATCCTM $155^{\circledR}$ or E. coli DH5 $\alpha^{\circledR}$ was cultured in TSB, $250 \mathrm{rpm}, 37^{\circ} \mathrm{C}, 12-16 \mathrm{~h}$ (overnight culture) and diluted to $1 \times 10^{4} \mathrm{cfu} / \mathrm{ml}$ using a 0.5 McFarland standard, a turbidity standard which is equivalent to $10^{7}-10^{8} \mathrm{cfu}$ of S. aureus (PML Microbiologicals, Wilsonville, OR). To evaluate surface colonization, $0.5 \mathrm{ml}$ of the diluted culture was incubated with rods for $2,5,8,12$, or $30 \mathrm{~h}$ at $37^{\circ} \mathrm{C}$ under static conditions. At each time period, 5 control and 5 Vanc-Ti rods were removed. Each rod was washed 7 times with phosphate-buffered saline (PBS), to remove non-adherent bacteria. Two rods were used to determine surface bacterial adhesion/viability and 3 were used for measurement of numbers of adherent bacteria. Additionally, 3 control and 3 Vanc-Ti rods per time point were processed for SEM.

\subsection{Effect of serum on microbiocidal activity}

Control and Vanc-Ti rods were incubated with complete fetal bovine serum (FBS, Atlanta Biochemicals) or $\mathrm{dH}_{2} \mathrm{O}$ statically at $37^{\circ} \mathrm{C}$ for $24-48 \mathrm{~h}$. Rods were removed and either fixed with $4 \%$ paraformaldehyde for $5 \mathrm{~min}$ and immunostained for fibronectin, or incubated with $1 \times 10^{4} \mathrm{cfu} / \mathrm{ml}$ S. epidermidis for $24 \mathrm{~h}$ and evaluated as above.

\subsection{Determination of biofilm formation}

Biofilms were stained with crystal violet using a modification of the method of O'Toole et al. [18]. Specifically, $0.5 \mathrm{ml}\left(C_{i}=10^{4} \mathrm{cfu} / \mathrm{ml}\right)$ of S. epidermidis cultures were statically incubated in 24 well plates containing control or Vanc-Ti rods for 2,5 , or $8 \mathrm{~h}$ at $37^{\circ} \mathrm{C}$. The medium containing non-adherent bacteria was carefully removed and Vanc-Ti and control rods moved to fresh wells. These rods were washed $6 \mathrm{X}$ with PBS and then stained, in a new well, with $1 \mathrm{ml}$ of PBS containing $100 \mu \mathrm{l}$ of $1 \%(\mathrm{w}: \mathrm{v})$ crystal violet (Sigma-Aldrich, St. Louis, MO) and incubated for $15 \mathrm{~min}$ at room temperature. The rods in the wells were washed 3 times with PBS and crystal violet then solubilized by addition of $2 \mathrm{ml}$ of $95 \% \mathrm{EtOH}$, with rocking for $15 \mathrm{~min}$; absorbance was measured $(\lambda=570 \mathrm{~nm})$ using a SPECTRAFluorPlus fluorimeter (Tecan, Research Triangle Park, NC).

\subsection{Rod activity following repeated bacterial challenges}

Control or Vanc-Ti rods that had been incubated with S. epidermidis in TSB for $24 \mathrm{~h}$ were cleaned by washing with $1 \%$ Triton X-100 and $10 \%$ sodium lauryl sulfate (Fisher Scientific) in $\mathrm{dH}_{2} \mathrm{O}$ for $24 \mathrm{~h}$. They were then washed 5 times with PBS, sterilized with $70 \% \mathrm{EtOH}$ for $15 \mathrm{~min}$, and washed twice with TSB. Cleaned rods were incubated with $1 \times 10^{4} \mathrm{cfu} / \mathrm{ml} \mathrm{S}$. epidermidis in TSB at $37^{\circ} \mathrm{C}$ for $24 \mathrm{~h}$. Following washing 5 times with PBS, the rods were assayed for bacterial adhesion/viability (first re-challenge). Each re-challenge involved an additional round of washing and culturing with S. epidermidis as described above.

\subsection{Evaluation of development of resistance}

S. epidermidis was cultured $\left(C_{i}=10^{4} \mathrm{cfu} / \mathrm{ml}\right)$ in TSB and incubated with the VancTi rods for up to 8 weeks, with TSB replaced every 3-4 days. Weekly, the rods were removed from the medium, sonicated in TSB to suspend adherent bacteria, and $200 \mu \mathrm{l}$ plated on agar plates. These colonies were assessed by the Thomas Jefferson University Clinical Microbiology Labs for resistance using growth on vancomycin plates $(6 \mu \mathrm{g} / \mathrm{ml})$ as well as the Kirby-Bauer disk diffusion assay.

\subsection{Quantitative measure of adherent bacteria}

Adherent bacteria were detached by sonication for $10 \mathrm{~min}$ in $1 \mathrm{ml} \mathrm{TSB}$, followed by vortexing for $2 \mathrm{~min}$, using a modification of the method of Barth et al. [19]. Total numbers of bacteria were determined by serial dilutions on TSB agar plates; the plates were incubated at $37^{\circ} \mathrm{C}$ for $24 \mathrm{~h}$, and colonies counted. For detection of slow growing colonies, those plates exhibiting no growth after $24 \mathrm{~h}$ were incubated for an additional $24 \mathrm{~h}$. Numbers of released bacteria were calculated, based on dilution and expressed as a function of rod weight.

\subsection{Fluorescent staining of adherent bacteria}

To remove non-adherent bacteria, rods were washed 7 times with PBS. These were stained using the Live/Dead ${ }^{\circledR}$ BacLightTM Viability Kit (Invitrogen) for 15 min to fluorescently label viable bacteria, followed by three PBS washes to remove nonspecific stain. Fluorescent, adherent bacteria were visualized by confocal laser microscopy (Olympus Fluoview 300).

\subsection{Immunohistological detection of vancomycin and fibronectin}

Rods were washed twice with PBS and incubated with a primary antibody against vancomycin (mouse anti-vancomycin IgG, 1:500, US Biologicals) in PBS $4{ }^{\circ} \mathrm{C}$ $2 \mathrm{~h}$. For visualizing fibronectin, after incubation in FBS, rods were fixed with $4 \%$ paraformaldehyde, incubated with rabbit anti-bovine fibronectin IgG (1:500, Invitrogen) in PBS, $4^{\circ} \mathrm{C}, 2 \mathrm{~h}$. They were then washed 3 times with PBS, incubated in PBS for $30 \mathrm{~min}$, and then treated with AlexaFluor 488-coupled donkey anti-rabbit or anti-mouse IgG (1:500, Invitrogen) in PBS, $1 \mathrm{~h}$, followed by 5 PBS washes and incubation in PBS for $30 \mathrm{~min}$. Stain was visualized by confocal laser microscopy (Olympus Fluoview 300).

\subsection{Scanning electron microscopy}

Vanc-Ti rods were incubated with S. epidermidis for $24 \mathrm{~h}$ in TSB. Samples were washed extensively up to 6 times in PBS and fixed with $2.5 \%$ glutaraldehyde in $0.1 \mathrm{~mol} / \mathrm{L}$ piperazine-1,4-bis(2-ethanesulfonic acid) buffer ( $\mathrm{pH}$ 7.4) for $5 \mathrm{~min}$. Following fixation, the samples were stained with $1 \% \mathrm{OsO}_{4}$ in $0.1 \mathrm{~mol} / \mathrm{L}$ piperazine-1,4-bis(2-ethanesulfonic acid) buffer ( $\mathrm{pH} 6.8$ ) for $1 \mathrm{~h}$ and then re-stained with $2 \%$ uranyl acetate for $1 \mathrm{~h}$. The rods were dehydrated in ethanol and sputter-coated with gold. Surfaces were visualized using an FEI Strata ${ }^{\mathrm{TM}}$ DB235 focused ion beam SEM (FEI Co, Hillsboro, OR).

\subsection{Statistics}

Experiments were performed a minimum of 3 independent times using at least 3 randomly chosen samples for each repeat. To establish significance, a one-tailed Student's $t$ test was used $\left({ }^{*} p<0.05\right)$. The results were tested by the KolmogorovSmirnov normality tests. 


\section{Results}

\subsection{S. epidermidis colonization of Vanc-Ti}

We first determined if the Vanc-Ti surface resists bacterial colonization over a $30 \mathrm{~h}$ time course (Fig. 1). To visualize bacterial colonization, we used the Live/Dead Assay in which viable bacteria stain with the membrane permeable Syto9 dye (green) but exclude propidium iodide (red); non-viable bacteria show both green and red staining. After incubation with S. epidermidis ATCC ${ }^{\mathrm{TM}} 155^{\circledR}$, the control surface evidences abundant fluorescence, indicating extensive bacterial colonization (Fig. 1A left, top panels). At 8, 12 and $30 \mathrm{~h}$, the intense fluorescence indicates the presence of bacterial foci, characteristic of biofilm formation. In contrast, when the Vanc-Ti rods are incubated with S. epidermidis, the fluorescence is very low at 8,12 and $30 \mathrm{~h}$ (bottom panels), indicating that Vanc-Ti rods resisted bacterial colonization. Only the green channel was imaged in these and subsequent pictures as dead cells did not remain adherent to the surfaces. We also examined the specificity of the treated surfaces. Vancomycin is active against Gram-positive, but not Gram-negative organisms. We therefore challenged the Vanc-Ti rod with a Gram negative organism, E. coli DH5 $\alpha^{\circledR}$. E. coli colonization is abundant on both the control and Vanc-Ti rods and colonization appeared to increase over time (Fig. 1A, right, top and bottom panels, respectively).

The number of $S$. epidermidis adherent to control Ti or Vanc-Ti rods were then quantified by direct plating. Bacterial numbers (colony forming units, cfu) are significantly $(p<0.05)$ lower on the
Vanc-Ti rod than on the control rod at 2 (40\% control), 5 (6.2\% of control), 8 (5.5\% of control), 12 (6.5\% of control), and 30 ( $0.4 \%$ of control) h (Fig. 1B, left). With E. coli, a Gram negative organism that is not susceptible to the Gram-positive-specific vancomycin, there were increased colony counts for both the control and Vanc-Ti rods with time, with no significant differences in numbers of colonies (Fig. 1B, right). S. epidermidis colonization is inhibited by Vanc-Ti where $E$. coli colonization readily occurred, indicating that the antibacterial properties of the surface duplicate the specificity of vancomycin, i.e., gram positive bacteria are susceptible whereas gram negative bacteria are not. Thus, whether evaluated directly using the live/dead fluorescence assay or by counting adherent bacteria, the results of this first study indicate that the Vanc-Ti rods specifically reduce bacterial adherence of gram positive organisms.

\subsection{Biofilm formation on Vanc-Ti}

The results described above suggested that Vanc-Ti, at the least, inhibited S. epidermidis adhesion. To learn if the antibiotic prevented biofilm formation, the rods were stained with crystal violet (Fig. 2A). Predictably, the stain on the control rods increases with time. These data suggested that the $S$. epidermidis adherent to the control rod have started to secrete a matrix; the Vanc-Ti rods show little evidence of matrix formation. Between 2 and $5 \mathrm{~h}$ and between 5 and $8 \mathrm{~h}$, significant increases in crystal violet staining is evident on the control rods. This elevated level of crystal violet incorporation is maintained up to $12 \mathrm{~h}$; after this time, there is a decline, presumably due to normal bacterial death in the now-established
A

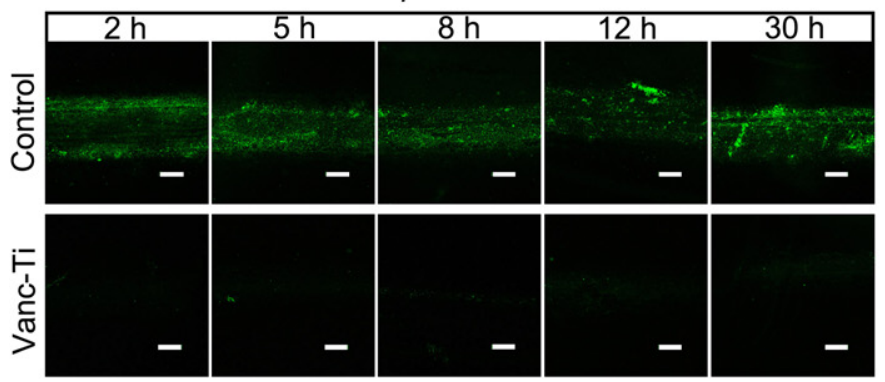

S.epidermidis
B

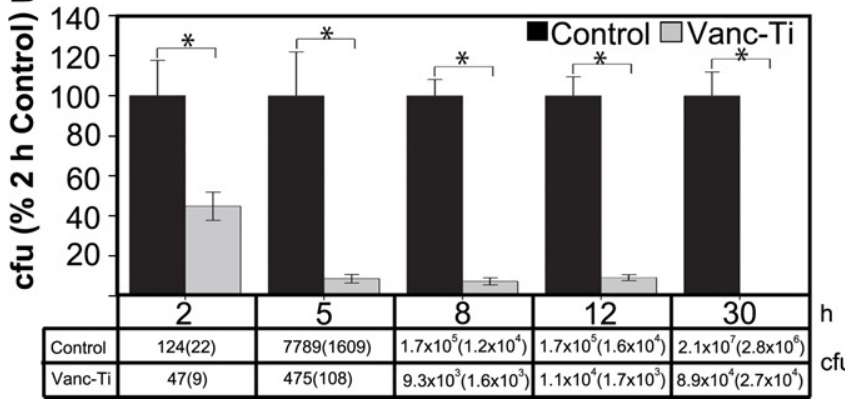
cfu(S..E.M.)
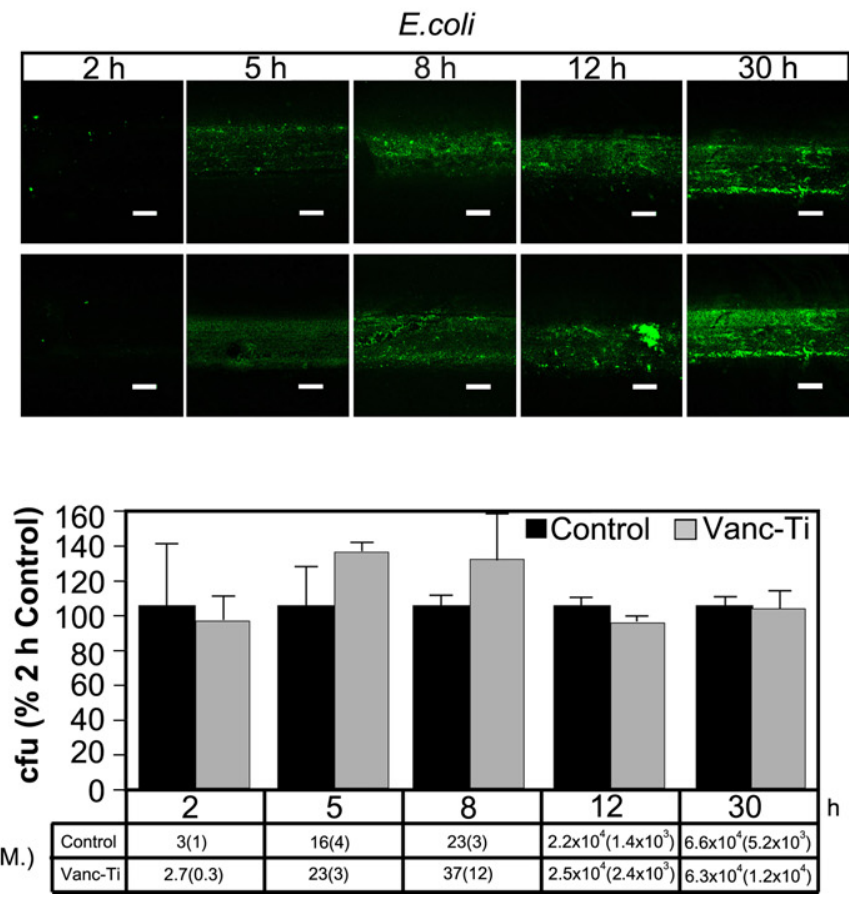

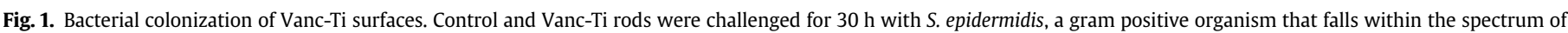

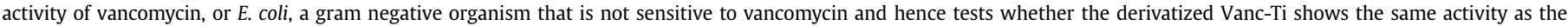

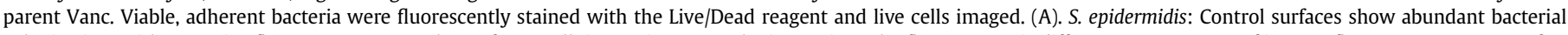

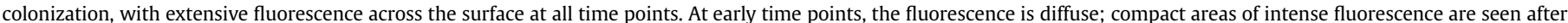

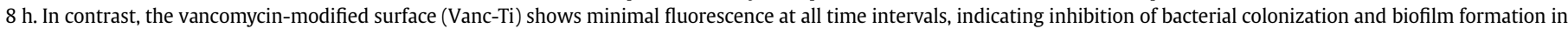

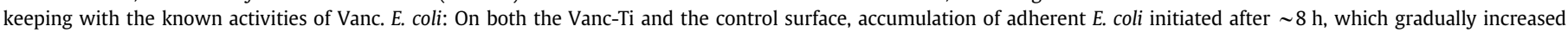

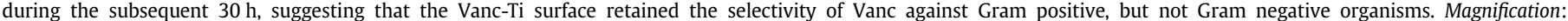

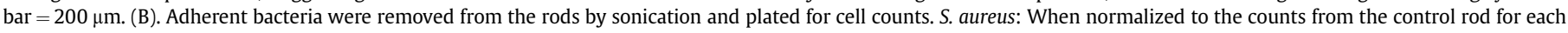

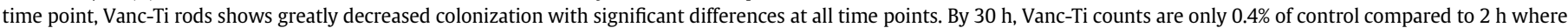

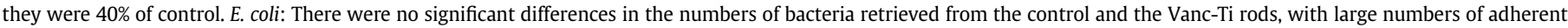

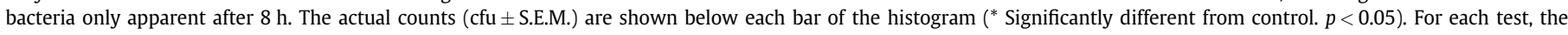

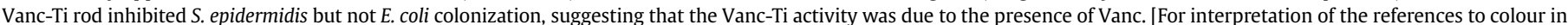
this figure legend, the reader is referred to the web version of this article.] 

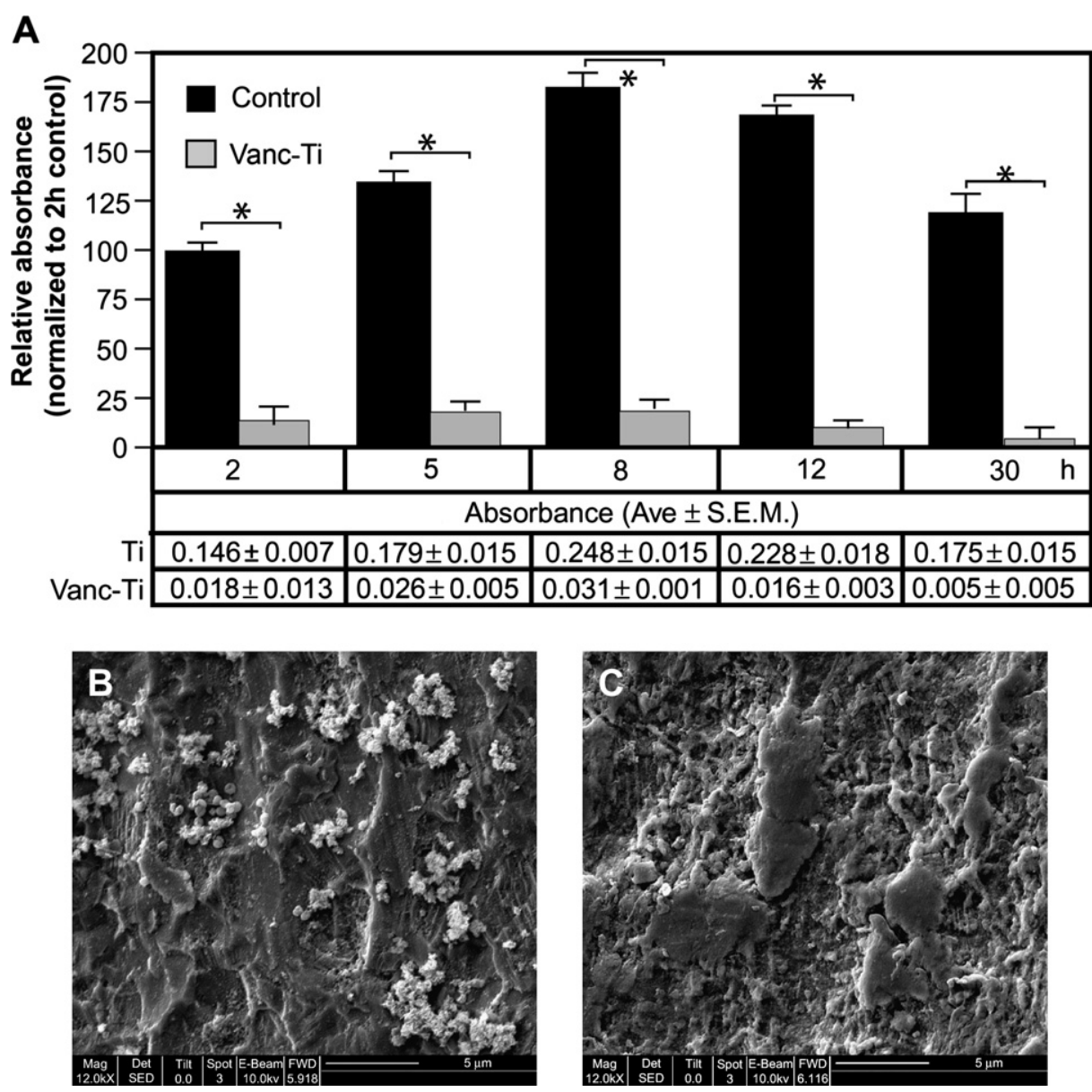

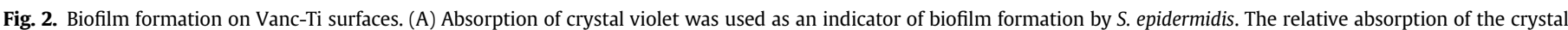

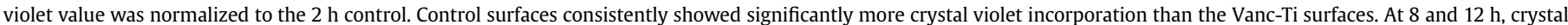

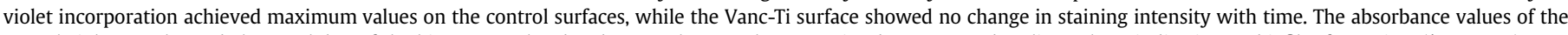

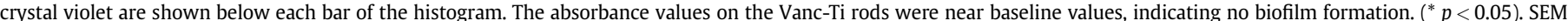

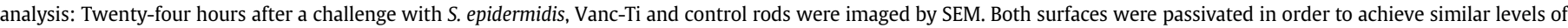

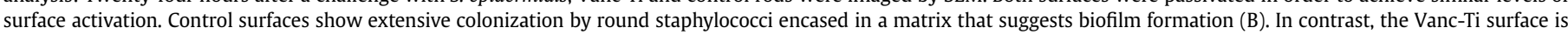
devoid of such colonization, with a few single bacterial-like particles observed (C). Magnification: bar $=5 \mu \mathrm{m}$.

biofilm [3-7]. At all time points, however, crystal violet staining of the Vanc-Ti rods is significantly lower than the control rods. In fact, at the end of the $30 \mathrm{~h}$ incubation period, crystal violet incorporation on the Vanc-Ti surface approaches zero, indicating that the Vanc-Ti surface significantly prevents biofilm formation.

SEM was used to further examine biofilm formation on Vanc-Ti rods that had been incubated with S. epidermidis for $24 \mathrm{~h}$ (Fig. 2B, $\mathrm{C})$. The surface displayed an overall roughness due to the presence of small pits; some smoothening is seen when the vancomycin is covalently attached to the Ti alloy. After colonization with S. epidermidis, the control surface displays multiple small, spherical bacteria (diameter $\approx 0.3-1 \mu \mathrm{m}$ ) of a size consistent with the Staphylococci and that conglomerate in grapelike clusters that are characteristic of Staphylococci (Fig. 2B). Importantly, the clustering and the appearance of multiple, small protrusions on the bacteria are consistent with initiation of slime/glycocalyx formation. In contrast to the control surface, the Vanc-Ti surface (Fig. 2C) displays only isolated individual bacteria; the absence of clustering lends strength to the notion that biofilm is not formed on the Vanc-Ti surface.

\subsection{Multiple S. epidermidis challenges of Vanc-Ti}

Since an implant must maintain anti-bacterial activity in the face of multiple bacterial challenges, we evaluated colonization following seven separate cycles of a $24 \mathrm{~h}$ exposure to S. epidermidis (Fig. 3). After each cycle of cleaning and re-exposure to bacteria, the control rods continue to exhibit high live/dead fluorescence as evidenced by measurement of fluorescent area (Fig. 3A), with the direct observation of adherent bacteria shown in Fig. 3B. When the rod fluorescence was quantified by densitometry (Fig. 3A, controls set to $100 \%$ ), throughout the first 4 cycles of repeat challenges, Vanc-Ti rods retain their ability to resist colonization. After 5 cycles, both the control and Vanc-Ti rods show a low level of variability in the extent of colonization. By observation, the control rods showed abundant fluorescence, indicative of abundant colonization (Fig. 3B, top panel). In contrast, the Vanc-Ti rods show a low level of fluorescence and hence minimal colonization (Fig. 3B, bottom panel). The results support the contention that the Vanc-Ti rods retain their activity in the face of multiple challenge exceptionally large initial numbers ( $>10^{7} \mathrm{cfu}$ ) of $S$. epidermidis.

\subsection{Vanc-Ti activity after serum coverage}

We next determined if the antibiotic would remain effective after incubation with serum proteins (Fig. 4). Incubation in FBS causes deposition of fibronectin on the control and Vanc-Ti rods; fibronectin staining is absent from rods that had not been exposed to serum (Fig. 4A, left). When the rods were probed for vancomycin coverage using immunofluorescence, abundant fluorescence is 
A

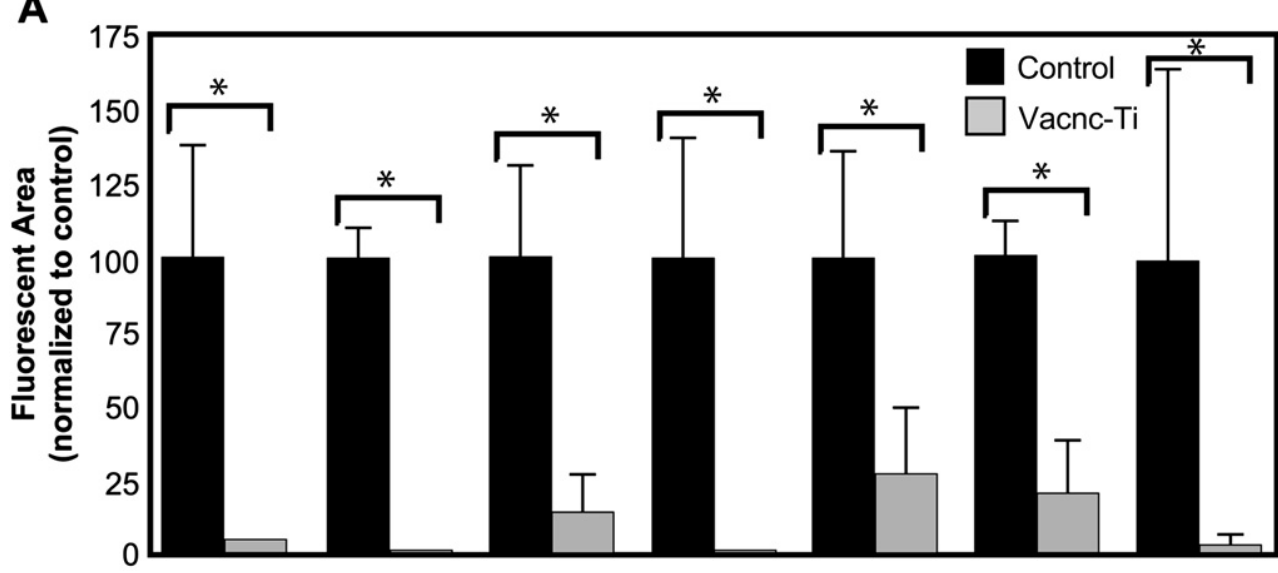

B

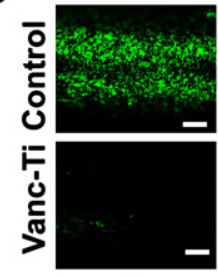

1

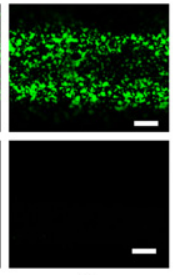

2

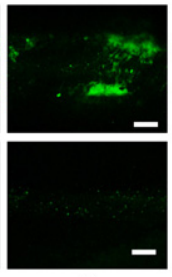

3

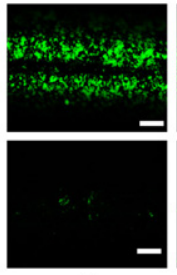

4

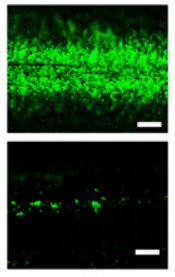

5

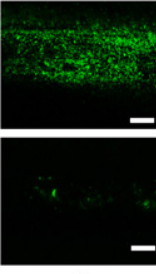

6

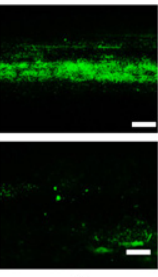

7

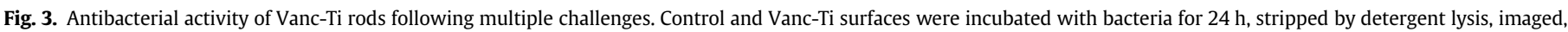

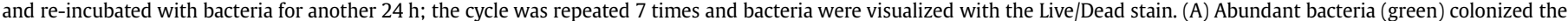

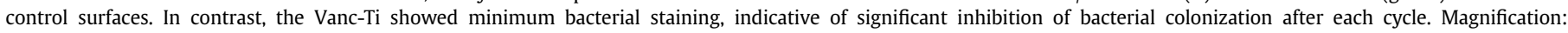

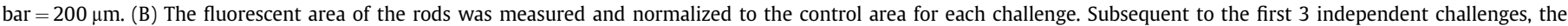

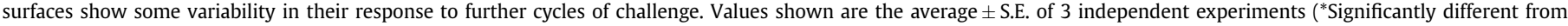
control, $p<0.05$ ). [For interpretation of the references to colour in this figure legend, the reader is referred to the web version of this article.]

observed over the surface of the Vanc-Ti rods exposed to FBS; control rods show no detectable fluorescence (Fig. 4A, right). Consequently, extensive coating with serum protein does not mask the ability of the covalently-tethered vancomycin to bind antibody. To learn if serum proteins affect the antibacterial activity of the surfaces, the rods were challenged with $S$. epidermidis $\left(C_{i}=10^{4} \mathrm{cfu} /\right.$ $\mathrm{ml}$ ) for $24 \mathrm{~h}$. Abundant bacterial colonization is observed on the control rods, regardless of pre-incubation in $\mathrm{dH}_{2} \mathrm{O}$ or FBS (Fig. 4B). Importantly, Vanc-Ti rods show minimum bacterial colonization, independent of surface serum absorption.

\subsection{Bacterial susceptibility after Vanc-Ti incubation}

Finally, we determined if continuous exposure of $S$. epidermidis to the Vanc-Ti rods, in vitro, would foster emergence of resistant bacteria. After 8 weeks of continuous exposure to control or Vanc-Ti surfaces, both planktonic and adherent bacteria were assessed for vancomycin sensitivity. Bacteria incubated under these conditions fail to grow (24-64 h assessment) on bacterial plates containing $6 \mu \mathrm{g} / \mathrm{ml}$ vancomycin, indicating that MIC for vancomycin for these bacteria is below $6 \mu \mathrm{g} / \mathrm{ml}$. These bacterial samples were then further characterized using the Kirby-Bauer disk diffusion assay $[20,21]$. Strains derived from control rods exhibit a zone of inhibition of $17.69 \pm 0.26 \mathrm{~mm}$, whereas those derived from Vanc-Ti rods showed a zone of $17.59 \pm 0.42 \mathrm{~mm}$. Importantly, no stray colonies grew in the cleared zones.

\section{Discussion}

Implant-associated, periprosthetic infections pose immense challenges to the medical community and imparts a huge economic burden on society. The ability of microorganisms to colonize implant surfaces and form biofilms is the critical step in the initiation of PPI. Once encased in a biofilm, bacteria become recalcitrant to immune surveillance and antibiotic therapy is of limited value. Herein, we address this problem by reporting that modifications of the $\mathrm{Ti}$ alloy surface with covalently tethered vancomycin is protective against both bacterial adhesion and biofilm formation by S. epidermidis. This organism together with $S$. aureus account for over $90 \%$ of implant-associated infections, and because of the avidity with which $S$. epidermidis forms biofilms, it is especially difficult to eradicate [22-25]. We show that $S$. epidermidis readily colonizes Ti alloy rods and forms a biofilm. When these rods are covalently derivatized with vancomycin, colonization is inhibited and biofilm formation is minimized. Remarkably, inhibition is maintained in the face of multiple challenges with bacteria in numbers that far exceed those encountered in vivo, and adsorbed serum proteins do not alter the activity of the tethered antibiotic. Together these in vitro studies suggest that we have prepared a novel surface that exhibits sustained activity against a major pathogen and that activity is maintained without fostering emergence of resistant bacterial strains.

We monitored biocidal activities of the Vanc-Ti surface using a number of different techniques: $S$. epidermidis viability, adhesion, biofilm formation, SEM and microbiological counting. The use of crystal violet, an agent that is retained in the secreted glycocalyx and reacts with peptidoglycans and teichoic acids, provided useful insight into biofilm formation. The observation that there was an elevation in the crystal violet retention with time indicated that $S$. epidermidis was not merely adhering to the Ti surface but synthesizing a protective biofilm. The fact that crystal violet absorption did not appreciably increase after 12 h reflected early 
A
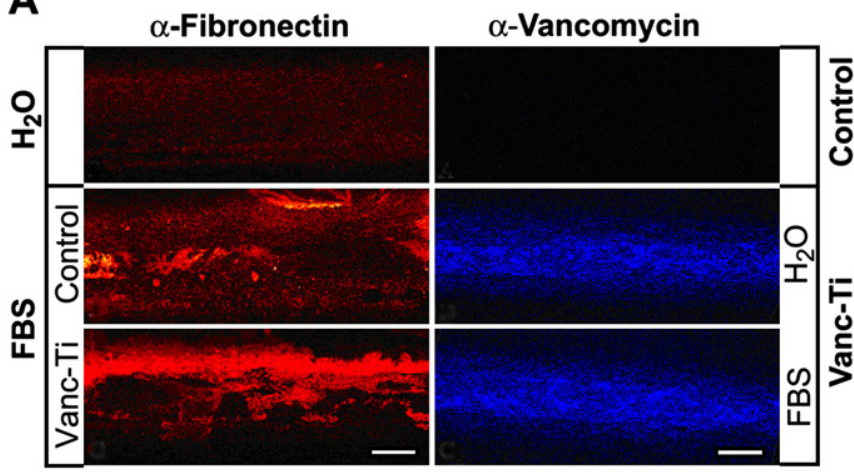

B

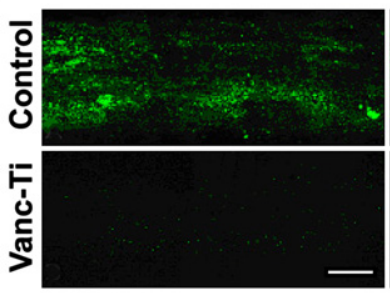

$\mathrm{H}_{2} \mathrm{O}$

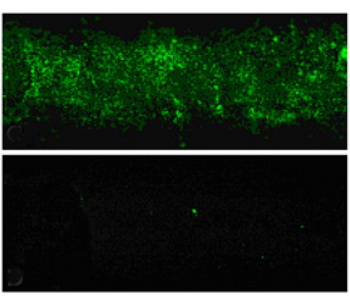

FBS

Fig. 4. Antimicrobial activity of the Vanc-Ti surface in the presence of serum. (A) Fibronectin adsorption and vancomycin fluorescence. (Left) Control or Vanc-Ti rods were incubated with FBS for $24 \mathrm{~h}$ and fibronectin adsorption detected by immunofluorescence analysis. Both surfaces showed abundant fibronectin (red stain), compared to the rods incubated in $\mathrm{H}_{2} \mathrm{O}$. (Right) Following incubation with serum proteins, rods were incubated with an antibody against vancomycin and visualized by immunofluorescence. Despite protein adsorption, vancomycin fluorescence (blue stain) was clearly detectable on the Vanc-Ti rods, with no staining on control surfaces. (B) Antimicrobial activity. Vanc-Ti rods that had been treated with serum proteins were challenged with $S$. epidermidis for $24 \mathrm{~h}$ and live, adherent bacteria stained with the Live/Dead kit (green). Fluorescence detected from the serum-treated Vanc-Ti rods was very low and similar to the fluorescence detected from the $\mathrm{H}_{2} \mathrm{O}$-incubated Vanc-Ti rods. In both cases, this fluorescence was much less intense than the fluorescent yield generated by bacteria that had colonized the control rods. Magnification: bar $=200 \mu \mathrm{m}$.

proliferative activities of the adherent bacteria on the control surface and probably activation of quorum sensing proteins to form the stable biofilm [26-28]. A second important indicator of biofilm formation was microbiological counting. While the latter technique provided a quantitative estimate of the number of viable bacteria, its use was dependent on the strength of adhesion (a variable quantity) to the implant surface and the ability to completely transfer and adequately sample the transported bacteria. Despite these drawbacks, the bacterial number was significantly lower on the Vanc-Ti surface than the controls at all times sampled. Noteworthy, perusal of the actual data indicates that there was considerable variation in bacterial counts, especially at long time intervals. Much of this variation was due to the high bacterial number utilized for the study. Furthermore, the adherent bacteria on the control surfaces tended to be associated with biofilms which would decrease the efficiency of suspension. Any adherent bacteria on the Vanc-Ti surfaces tended to be in small colonies with limited biofilm formation, allowing a more efficient suspension of these bacteria. Therefore, comparisons of the recovered bacteria from control vs. Vanc-Ti surfaces tended to underestimate differences. Nevertheless the very large differences in bacterial numbers between the tethered vancomycin and the control rods lend strong direct support to the contention that the antibiotic retained its biocidal activities and inhibited biofilm formation, two major events in PPI development.

Cognizant of the fact that PPI probably results from one or more episodes of exposure to blood-borne organisms, we evaluated the impact of multiple challenges with S. epidermidis. Using numbers of organisms that were many orders of magnitude greater than might be expected in vivo, we found that the Vanc-Ti surface was biocidal for four or possibly more challenges with $S$. epidermidis. The fact that the surface remained active over the $24 \mathrm{~h}$ of the challenge and that re-challenges resulted in continued activity raises interesting questions about interactions of the geometrically-constrained antibiotic (i.e., surface-tethered) with the bacterial membrane. As is the case for the antibiotic in solution, we would hypothesize that vancomycin was bound reversibly to the Lys-D-Ala-D-Ala peptidoglycan that cross linked the bacterial cell wall. After bacteriolysis occurred, the reversible vancomycin-peptidoglycan interaction would result in release of any bacterial remnants, leaving the surface-bound vancomycin free to engage other bacteria. While it is also likely that some vancomycin was degraded, there were, based on the data, sufficient numbers of antibiotic molecules tethered to the Ti surface to maintain a high level of activity as the rod was assailed with successive rounds of bacterial challenges. Probably, both the high local concentration of attached antibiotic molecules together with the reversible nature of the drug-bacteria interaction would together serve to maintain the activity of the nano-engineered Ti surface.

It could be argued that while the Vanc-Ti surface inhibited colonization of S. epidermidis, a Gram positive organism, inhibition was due to alterations in surface charge rather than the presence of a tethered antibiotic. Indeed, when the surfaces were examined by SEM, some differences in the topography were seen, mainly reflecting a small change in overall roughness. This change could promote bacterial adhesion. To exclude this possibility, we evaluated the effect of the antibiotic on a Gram negative organism, E. coli. We noted that unlike the studies with $S$. epidermidis, the Vanc-Ti surface had minimal effect on $E$. coli adhesion and bacterial counts. Thus the Vanc-Ti surface supported E. coli adherence, whereas S. epidermidis adherence was inhibited. The data strongly suggested that the tethered vancomycin acts as an antibiotic against a specific class of organisms and its biocidal properties did not merely reflect changes in surface structure.

An important final test of the utility of the methodology was the demonstration that the Vanc-Ti rods did not foster the emergence of resistant S. epidermidis even after prolonged exposures. Using the conventional Kirby-Bauer diffusion assay with the CLSI vancomycin standards[30], our strain of S. epidermidis (ATCC ${ }^{\mathrm{TM}} 155^{\circledR}$ ) exhibited a zone of inhibition of $\sim 17.6 \mathrm{~mm}$; this was unchanged after 4 weeks of exposure to the Vanc-Ti rods. Furthermore, the absence of stray colonies in the zones of inhibition indicated that we could detect no subsets of insensitive or resistant bacteria. Thus, unlike controlled release systems where decreasing levels of antibiotic can provide a selective growth advantage, the tethered vancomycin was stably present at high surface concentrations [29] and therefore does not confer such an advantage.

\section{Conclusions}

We have shown that vancomycin covalently tethered to a $\mathrm{Ti}$ alloy surface prevents bacterial colonization and biofilm formation. Moreover, the tethered antibiotic is stable, maintains its activity even when challenged multiple times with bacteria and does not foster resistance. Since $S$. epidermidis infection is closely linked to the pathogenesis of PPI, the Vanc-Ti system holds promise of controlling or even preventing this devastating orthopaedic condition.

\section{Acknowledgments}

We thank the NIH (grants DE-13319, DE-10875, and AR-051303) and the Department of Defense (grant DAMD17-03-1-0713) for funding for this study. Results presented are not the statement or policy of the funding agencies. 


\section{References}

[1] Darouiche RO. Treatment of infections associated with surgical implants. The New England Journal of Medicine 2004;350:1422-9.

[2] Gristina AG, Oga M, Webb LX, Hobgood CD. Adherent bacterial colonization in the pathogenesis of osteomyelitis. Science 1985;228:990-3.

[3] Costerton JW, Lewandowski Z, Caldwell DE, Korber DR, Lappin-Scott HM. Microbial biofilms. Annual Review of Microbiology 1995;49:711-45.

[4] Donlan RM, Costerton JW. Biofilms: survival mechanisms of clinically relevant microorganisms. Clinical Microbiology Reviews 2002;15:167-93.

[5] Stoodley P, Sauer K, Davies DG, Costerton JW. Biofilms as complex differentiated communities. Annual Review of Microbiology 2002;56:187-209.

[6] Bahar G. Biofilms, tolerance and antimicrobial resistance. Mikrobiyoloji Bulteni 2002;36:343-51.

[7] Stewart PS, Costerton JW. Antibiotic resistance of bacteria in biofilms. Lancet 2001;358:135-8.

[8] Toms AD, Davidson D, Masri BA, Duncan CP. The management of peri-prosthetic infection in total joint arthroplasty. The Journal of Bone and Joint Surgery - British Volume 2006;88:149-55.

[9] Nelson CL. The current status of material used for depot delivery of drugs. Clinical Orthopaedics and Related Research 2004;427:72-8.

[10] Radin S, Ducheyne P, Kamplain T, Tan BH. Silica sol-gel for the controlled release of antibiotics. I. Synthesis, characterization, and in vitro release. Journal of Biomedical Materials Research 2001;57:313-20.

[11] Vodna L, Bubenikova S, Bakos D. Chitosan based hydrogel microspheres as drug carriers. Macromolecular Bioscience 2007;7:629-34.

[12] Vandenbulcke K, Horvat LI, De Mil M, Slegers G, Beele H. Evaluation of the antibacterial activity and toxicity of 2 new hydrogels: a pilot study. The International Journal of Lower Extremity Wounds 2006;5:109-14.

[13] Burny F, Donkerwolcke M, Moulart F, Bourgois R, Puers R, Van Schuylenbergh $\mathrm{K}$, et al. Concept, design and fabrication of smart orthopedic implants. Medical Engineering and Physics 2000;22:469-79.

[14] Fairman R, Akerfeldt KS. Peptides as novel smart materials. Current Opinion in Structural Biology 2005;15:453-63.

[15] Antoci Jr V, King SB, Jose B, Parvizi J, Zeiger AR, Wickstrom E, et al. Vancomycin covalently bonded to titanium alloy prevents bacterial colonization. Journal of Orthopaedic Research 2007;25:858-66.

[16] Jose B, Antoci Jr V, Zeiger AR, Wickstrom E, Hickok NJ. Vancomycin covalently bonded to titanium beads kills Staphylococcus aureus. Chemistry and Biology 2005;12:1041-8.
[17] Edupuganti OP, Antoci Jr V, King SB, Jose B, Adams CS, Parvizi J, et al. Covalent bonding of vancomycin to Ti6Al4V alloy pins provides long-term inhibition of Staphylococcus aureus colonization. Bioorganic and Medicinal Chemistry Letters 2007;17:2692-6.

[18] O'Toole GA, Pratt LA, Watnick PI, Newman DK, Weaver VB, Kolter R. Genetic approaches to study of biofilms. Methods in Enzymology 1999;310:91-109.

[19] Barth E, Myrvik QM, Wagner W, Gristina AG. In vitro and in vivo comparative colonization of Staphylococcus aureus and Staphylococcus epidermidis on orthopaedic implant materials. Biomaterials 1989;10:325-8.

[20] Boyle VJ, Fancher ME, Ross Jr RW. Rapid, modified Kirby-Bauer susceptibility test with single, high-concentration antimicrobial disks. Antimicrobial Agents and Chemotherapy 1973;3:418-24.

[21] Biemer JJ. Antimicrobial susceptibility testing by the Kirby-Bauer disc diffusion method. Annals of Clinical and Laboratory Science 1973;3:135-40.

[22] Vuong C, Otto M. Staphylococcus epidermidis infections. Microbes and Infection 2002:4:481-9.

[23] Oliveira M, Bexiga R, Nunes SF, Carneiro C, Cavaco LM, Bernardo F, et al. Biofilm-forming ability profiling of Staphylococcus aureus and Staphylococcus epidermidis mastitis isolates. Veterinary Microbiology 2006;118:133-40.

[24] Peersman G, Laskin R, Davis J, Peterson M. Infection in total knee replacement: a retrospective review of 6489 total knee replacements. Clinical Orthopaedics and Related Research 2001;392:15-23.

[25] Kilgus DJ, Howe DJ, Strang A. Results of periprosthetic hip and knee infections caused by resistant bacteria. Clinical Orthopaedics and Related Research 2002:116-24.

[26] Costerton JW, Stewart PS, Greenberg EP. Bacterial biofilms: a common cause of persistent infections. Science 1999;284:1318-22.

[27] Costerton W, Veeh R, Shirtliff M, Pasmore M, Post C, Ehrlich G. The application of biofilm science to the study and control of chronic bacterial infections. The Journal of Clinical Investigation 2003;112:1466-77.

[28] Costerton JW. Biofilm theory can guide the treatment of device-related orthopaedic infections. Clinical Orthopaedics and Related Research 2005:7-11.

[29] Antoci Jr V, Adams CS, Parvizi J, Ducheyne P, Shapiro IM, Hickok NJ. Covalently attached vancomycin provides a nanoscale antibacterial surface. Clinical Orthopaedics and Related Research 2007:461:81-7.

[30] Clinical and Laboratory Standards Institute. Performance standards for antimicrobial susceptibility testing: eighteenth informational supplement, M100-S18, vol. 28; January 2008. No. 1. 